\title{
Assessment of Mothers Level of Knowledge About Neonatal Danger Signs and Its Associated Factors in St Paul's Hospital Millenium Medical College Addis Ababa Ethiopia
}

\author{
Michael Tamene Haile \\ Neonatal nursing department, St Paul's Hospital Millennium Medical College \\ Addis Ababa, Ethiopia, P.O. Box 1271
}

\begin{abstract}
Background: Neonatal danger has become a substantial problem in many developing countries like Ethiopia. More specifically, neonatal rates in Ethiopia are among the highest in the world. In this regard, health-seeking behavior of mothers for neonatal care highly relies on their knowledge about neonatal danger sign, and it has been hardly investigated. Therefore, this study was intended to determine the level of mother's knowledge about neonatal danger signs and to identify factors associated with good mother's knowledge.

Objective: To assess mother's level of knowledge about neonatal danger sign and its associated factors in St. Paul Hospital, Addis Ababa, Ethiopia.

Methods: Institution based quantitative cross sectional study design was used to assess the knowledge and associated factors that influence neonatal danger signs knowledge among mothers attending postnatal. A total of 159 postnatal mothers was the calculated sample size and selected by simple random sampling technique. Data was collected by using a structured interview questionnaire through face to face interview by six data collectors. Data quality was assured through pretesting the questionnaire on 5\% of postnatal mothers and findings from the pretest was used to amend the questionnaire. The data was entered and analyzed by SPSS version 23.0.

Result: A total of 155 mothers were interviewed with the response rate of $97.5 \%$. The mean age of mothers was 28.8 ( $\mathrm{SD} \pm 5.4)$. More than one third (39.4\%) of mothers were in the age range 25-30 years. The majority of mothers were married, 140 (90.3\%); orthodox by religion, 84 (54.2\%) and Oromo by ethnic group which was 75 (48.7\%). Only $46(29.7 \%)$ of all mothers had good knowledge which were having knowledge of at least four of the ten defined neonatal danger signs. Fever was more commonly known danger sign by $55.6 \%$ of the mothers. There were no any significant associations based on multivariate logistic regression.

Conclusion and recommendations: Majority of mothers had poor knowledge of the majority of neonatal danger signs. Strengthening postnatal counselling at a health facility or dissemination of information community level about danger sign is highly recommended.
\end{abstract}

DOI: $10.7176 / \mathrm{JMPB} / 67-02$

Publication date:August $31^{\text {st }} 2020$

\section{Introduction}

The neonatal period is the first 28 days of life. It is the most vulnerable time for a child's survival. Globally, the main causes of neonate deaths are preterm birth complications, complications during labor and delivery (intrapartum-related complications), and sepsis. Together, these three causes account for almost three quarters of all neonatal deaths [1].

Almost half of the deaths in under-five-year-olds occur in infancy. Of the infant deaths, about two-thirds occur in the neonatal period. It has also been noted that one-third of all neonatal deaths occur on the first day of life, almost half within 3 days and nearly three-quarters within the first week of life [2].

In developing countries, about 34 of every 1000 live births result in neonatal death. The majority of new born deaths occur at home where a few families recognize signs of newborn illness and nearly all neonates are not taken to health facilities when they were sick [3].

Neonatal danger has become a substantial problem in many developing countries like Ethiopia. More specifically, neonatal rates in Ethiopia are among the highest in the world. In this regard, health-seeking behavior of mothers for neonatal care highly relies on their knowledge about neonatal danger sign, and it has been hardly investigated. [4]

It is estimated that $75 \%$ of neonatal deaths could be avoided with simple low cost tools like: antibiotics for pneumonia and sepsis, sterile blades to cut the umbilical cords, and using knit caps and kangaroo care to keep babies warm. This is only possible if mothers' knowledge regarding the above neonatal danger signs is good enough to make decision to seek health service. Different tools to facilitate identification of neonatal health problems and management were introduced into the health programs in several countries like Ethiopia. Integrated Management of Newborn and Childhood Illness developed by WHO was the one which focused on assessment of neonatal danger signs and apply prompt timely treatment. [5]

Even though there has been a good progress in reducing neonatal mortality and morbidity in the recent decade 
as compared to previous times, there are still a substantial number of neonates that lost their life due to the inability of low level of maternal danger sign knowledge. The 2016 EDHS findings indicate that all childhood mortality rates have declined over time. The neonatal mortality rate was 29 deaths per 1,000 live births, and the post-neonatal mortality rate was 19 deaths per 1,000 live births [3].

Many new-borns are often dying due to delay in recognizing danger signs, delay in deciding to get medical care and delay in reaching a health worker or facility. Behaviorally, modifiable factors such as poor recognition of neonatal danger signs, local illness beliefs, use of traditional/home remedies, and inability of mothers to identify health providers delayed the health care-seeking behavior of mothers for their new-born. The vast majority of neonates died at home due to mothers who did not seek care during the neonatal period. Early detection of neonatal illness and increasing facility births improve care-seeking behavior for neonatal illness [4].

The highest rates of neonatal death (34 deaths per 1,000 live births in 2011) are still in Sub-Saharan Africa, which accounts for 38\% of the global neonatal death. In Ethiopia, 120,000 babies die every year in the first 4 weeks of life. Neonates are more prone to show subtle signs of illness. Slowness or difficulty of feeding is sometimes the only signs present, and the three major causes of neonatal deaths worldwide are infections, diarrhea $(36 \%)$, prematurity $(28 \%)$ and birth asphyxia (23\%). Some of repeatedly reported neonatal danger signs include not able to feed, movement only when stimulated, low or high temperature, respiratory rate over 60 breaths per minute, severe chest in drawing and history of convulsion. Recognizing the occurrence of these signs will results in high overall sensitivity and specificity to predict the need for seeking treatment of the new born [5].

It is estimated that $75 \%$ of neonatal deaths could be avoided with simple low cost tools like: antibiotics for pneumonia and sepsis, sterile blades to cut the umbilical cords, and using knit caps and kangaroo care to keep babies warm. This is only possible if mothers' knowledge regarding the above neonatal danger signs is good enough to make decision to seek health service. Different tools to facilitate identification of neonatal health problems and management were introduced into the health programs in several countries like Ethiopia [5].

Several studies have been conducted in Ethiopia regarding the knowledge of mothers on danger sign in new born babies. Such studies have shown that, even though the knowledge and awareness of mothers regarding the danger sign of new born babies showed a considerable progress; still a tremendous effort have to be made by various parties to elevate the knowledge and awareness of postnatal mothers regarding basic danger signs. This study was aimed to assess the knowledge of mothers toward danger signs in new born babies at SPHMMC.

This study is believed that it provides vital information concerning the knowledge of mothers in neonatal danger signs. Moreover, the following points are the final contribution of our study.

* Determining the maternal level of knowledge regarding neonatal danger sign

* Providing information to policy makers who influence the program on maternal knowledge about Neonatal danger signs

\section{Objectives}

\section{General objective}

To assess maternal level of knowledge about neonatal danger sign and its associated factors in St. Paul Hospital, Addis Ababa, Ethiopia, March 2018.

Specific objective

- To determine the level of maternal knowledge on neonatal danger signs.

- To identify factors that affect the level of maternal knowledge in neonatal danger sign.

\section{Methodology}

\subsection{Study area}

This study was conducted in Addis Ababa, St Paul's Hospital Millenium College. Addis Ababa is the capital city of Ethiopia which have 10 sub city lay on 540 square kilometer surface area and at altitude ranging from 2,100 meter in the southern (Akaki Kality sub city) to 3,000 meter in northern (entoto) above sea level. Among these sub cities the northern part of the capital city is Gullele sub city in which st.paul's hospital millennium medical college the second largest national public general specialized referral hospital is located on the Piassa to Medianialem secondary high school striate road way at right side beside to the Ethiopian public health institute. The hospital was founded in 1961 E.C.by Emperor Hailesilassie with the help of the German Evangelical church by aiming mainly to serve payment free those economically under privileged population. Since 2007 G.C it has become medical college. The hospital is giving the services in its different branches and many different departments including internal medicine department, surgery department, neurology, ENT, psychiatry, ophthalmology, dentistry (maxillofacial surgery), radiology, dermatology, gynecology and obstetrics, pediatrics, biomedicine, emergency medicine, kidney transplant and medical school by using about 4000 staffs.

\subsection{Study design}

Institutional based cross-sectional study design was employed to undertake investigation since it's important for 
collection of information from the respondent and to look the problem at a specific time.

\subsection{Study period}

This study was conducted from April to July, 2018.

\subsection{Source of population}

All mothers who attend their postnatal follow up at SPHMMC.

\subsection{Study population}

Randomly selected (lottery method) mothers who attended postnatal follow up at SPHMMC during the study period

\subsection{Inclusion and Exclusion criteria}

\subsubsection{Inclusion criteria}

\subsubsection{Exclusion criteria}

- All postnatal mothers at SPHHMMC

- Mothers who were not interested to take part in the study.

- Mothers who were critically ill during the study period

\subsection{Operational definition}

Knowledge: the level of mothers who state at least four neonatal danger signs; defined on the basis of the score.

Good knowledgeable: Those mothers who are able to mention at least four danger signs of neonate out of ten without giving option of respected signs $(16,21)$.

Poor knowledgeable: Those mothers who are not able to mention at least four danger signs of neonate without giving option of respected signs $(16,21)$.

\subsection{Sampling Size and Sampling Procedure}

To determine the minimum number of mothers who were included in the study, the single population proportion formula The proportion of population possessing good knowledge assumed to $11.7 \%$ (7). So $n=159$.

\subsection{Data collection tools and methods}

Pre-tested and semi-structured interviewer administered questionnaire, which is developed after reviewing different literatures, was used to collect data. The questionnaire was prepared in English. The tool has three parts; Part I - socio demographic related questions, Part II - Obstetric related and, Part III was used to collect data about the level of knowledge toward neonatal danger signs related questions.

The total number of correct spontaneous responses to 10 items (neonatal danger signs) with a minimum score of 0 and maximum of 9 was used to measure knowledge of mothers about neonatal danger signs. Accordingly, two categories were developed for neonatal danger sign. Spontaneous response is respondents naming of neonatal danger signs without giving the option of the respected signs. Mothers who mentioned at least four neonatal danger signs were considered as having good knowledge about neonatal danger signs and mothers who mentioned less than four neonatal danger signs were considered as having poor knowledge. The study used primary data with semi structured interview questions to collect data.

\subsection{Data Quality Control and Management}

Questionnaires were pre-tested in other hospital having similar socio-demographic characteristics. Translator was used to translate the questionnaire into the language mothers' intended to speak to make data collection simple. Six well oriented health professionals conducted the data collection process. Data were checked for completeness, accuracy, clarity and consistency before data entry. Proper coding and categorization of data were maintained for the quality of the data to be analyzed. The consistency and clarity of questionnaire was checked continually.

\subsection{Data processing and analysis}

After collecting the data; it will be coded, edited, entered into a computer and cleaned. Then the data will be analyzed using statistical package for social sciences (SPSS version 23) to generate descriptive statistics: means, frequency, percentages and standard deviations. To determine an association between dependent and independent variables adjusted odds ratio will be used using logistic regression and the significance level will be determined using $\mathrm{p}<0.05$ or using confidence interval of $95 \%$. The finding will be displayed using tables, numbers, percentage and graphs. 


\subsection{Ethical Considerations}

This study was conducted by taking ethical permission from the Human Research Ethics Committees of SPHMMC. Efforts were done to overcome ethical concerns of the participant due to sensitivity of the issue under study by careful designing and structuring the questionnaire. Clear explanation about the purpose and usefulness of the study and by excluding names and other identifying numbers from the questionnaire in order to assure confidentialities of information and assure the respondent not participating in the research can't cause any harm.

\section{Results}

\subsection{Socio demographic characteristics}

In this study, a total of 155 mothers whose visit postnatal care department were interviewed with the response rate of $97.5 \%$. The mean age of mothers was $28.8(\mathrm{SD} \pm 5.4)$. More than one third $(39.4 \%)$ of mothers were in the age range 25-30 years. The majority of mothers were married, 140 (90.3\%); orthodox by religion, $84(54.2 \%)$ and Oromo by ethnic group which was $75(48.7 \%)$.

Concerning the educational status of mothers, one hundred forty-two (91.6\%) had attended formal school and $74(47.7 \%)$ had accomplished college and higher. Sixty-two (40.0\%) and forty-eight (31.0\%) of mothers were house wife and government employed respectively by their occupation. Out of the total study subjects, 113 (72.9\%) of mothers earn an average monthly income of higher than 1000 Birr. Regarding the husband's educational and occupational status, $128(90.8 \%)$ has attended formal education and majority of them, $59(40.7 \%)$, were private employed (Table 1).

Table 1: Socio-demographic characteristics of respondents attending SPHMMC, Addis Ababa, Ethiopia, 2018

\begin{tabular}{|c|c|c|}
\hline Characteristics & Number & Percent \\
\hline \multicolumn{3}{|l|}{ Age } \\
\hline $18-24$ & 34 & 21.9 \\
\hline 25-30 & 61 & 39.4 \\
\hline 31-35 & 43 & 27.7 \\
\hline$>35$ & 17 & 11.0 \\
\hline \multicolumn{3}{|l|}{ Marital status } \\
\hline Married & 140 & 90.3 \\
\hline Single & 11 & 7.1 \\
\hline Divorced & 4 & 2.6 \\
\hline \multicolumn{3}{|l|}{ Religion } \\
\hline Orthodox & 84 & 54.2 \\
\hline Catholic & 4 & 2.6 \\
\hline Protestant & 42 & 27.1 \\
\hline Muslim & 25 & 16.1 \\
\hline \multicolumn{3}{|l|}{ Ethnicity } \\
\hline Oromo & 75 & 48.7 \\
\hline Amhara & 43 & 27.9 \\
\hline Tigrie & 8 & 5.2 \\
\hline SNNPR & 28 & 18.2 \\
\hline \multicolumn{3}{|l|}{ Occupation } \\
\hline House wife & 62 & 40.0 \\
\hline Government employed & 48 & 31.0 \\
\hline Private employed & 40 & 25.8 \\
\hline Other & 5 & 3.2 \\
\hline \multicolumn{3}{|l|}{ Educational status } \\
\hline No formal education & 13 & 8.4 \\
\hline Primary education & 19 & 12.3 \\
\hline Secondary education & 49 & 31.6 \\
\hline Diploma & 49 & 31.6 \\
\hline Degree and above & 25 & 16.1 \\
\hline \multicolumn{3}{|l|}{ Monthly income in birr } \\
\hline$<1000$ & 18 & 13.8 \\
\hline 1000-1500 & 12 & 9.2 \\
\hline $1500-2000$ & 42 & 32.1 \\
\hline$>2000$ & 59 & 45.0 \\
\hline
\end{tabular}




\begin{tabular}{lll}
\hline Characteristics & Number & Percent \\
\hline Husband's education & & \\
$\quad$ No formal education & 13 & 9.2 \\
$\quad$ Primary education & 7 & 5.0 \\
Secondary education & 39 & 27.7 \\
Diploma & 26 & 18.4 \\
Degree and above & 56 & 39.7 \\
Husband's occupation & 3 & \\
Not employed & 52 & 3.1 \\
Government employed & 59 & 40.7 \\
$\quad$ Private employed & 26 & 17.9 \\
Daily laborer & 5 & 3.4 \\
Other & & \\
\hline
\end{tabular}

The family size of respondents and majority (51.3\%) of them were having 1-3 family size followed by 4-6 $(45.3 \%)$ and $7-10(3.3 \%)$.

One hundred five respondents $(67.7 \%)$ reported that they have functional radio, $135(87.1 \%)$ of them have functional television and $147(94.8 \%)$ of respondents have functional telephone including mobile phone. Regarding the types of communication media use for information, majority, 122 (78.7\%), used Television followed by Radio which was 25 (16.7\%) and Telephone (5.1\%). (Fig 2)

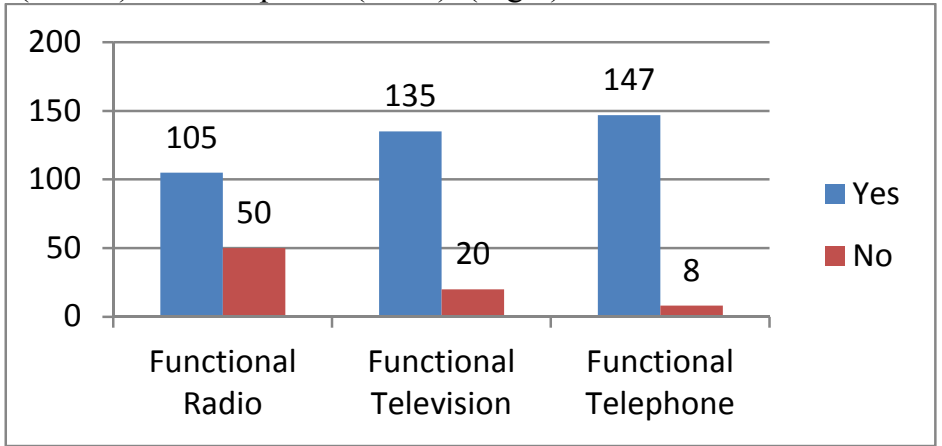

Figure 2: Availability of communication media of respondents attending SPHMMC, Addis Ababa, 2018

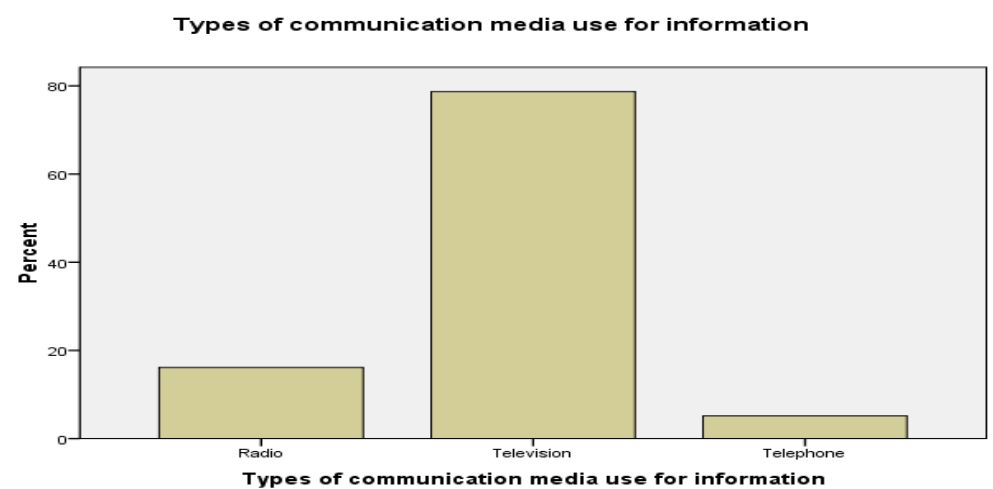

Figure 3: Types of communication media use of respondents attending SPHMMC, Addis Ababa, 2018

\subsection{Maternal health related factors}

Study subjects were asked about their history of pregnancy and delivery; in addition, ANC visits during pregnancy of the current neonate. Majority, 106 (68.4\%) and 112 (72.3\%), of mothers have a history of 1-2 pregnancies and deliveries respectively in their current life. One hundred forty three $(92.9 \%)$ respondent mothers visited health facility during current pregnancies with the reason of pregnant related problem $(9.8 \%)$, ANC $(88.8 \%)$ and health problem not related to pregnancy (1.4\%). Among those attended ANC, $111(78.2 \%)$ and $18(12.7 \%)$ of them were received ANC service at least once and more than four times during the pregnancy respectively. Furthermore, majority of mothers started ANC follow-up during second trimester (50.0\%) followed by first trimester (45.1\%) and third trimester $(4.9 \%)$.

One hundred seven (75.4\%) of the mothers were preferred place ANC follow-up at health center, 18(12.7\%) 
at Hospital and $17(12.0 \%)$ at private clinic with the reason of close to residence, competent health workers, fair price and other. Most, 151 (97.4\%), of mothers gave birth to their current child in health institutions (Table 2).

Table 2: Distribution of pregnancy and obstetrics related characteristics of respondents attending SPHMMC, Addis Ababa, Ethiopia, 2018.

\begin{tabular}{|c|c|c|}
\hline Characteristics & Number & Percent \\
\hline \multicolumn{3}{|l|}{ Gravida $(n=155)$} \\
\hline $1-2$ & 106 & 68.4 \\
\hline $3-5$ & 45 & 29.0 \\
\hline$>5$ & 4 & 2.6 \\
\hline \multicolumn{3}{|l|}{ Para $(n=155)$} \\
\hline $1-2$ & 112 & 72.3 \\
\hline $3-5$ & 40 & 25.8 \\
\hline$\geq 5$ & 3 & 1.9 \\
\hline \multicolumn{3}{|l|}{ Died children $(n=152)$} \\
\hline Never & 132 & 86.8 \\
\hline $1-2$ & 20 & 13.2 \\
\hline \multicolumn{3}{|c|}{ Visit Health facility during current pregnancy $(n=154)$} \\
\hline Yes & 143 & 92.9 \\
\hline No & 11 & 7.1 \\
\hline \multicolumn{3}{|l|}{ Reason for visit of Health facility $(n=143)$} \\
\hline Pregnant related problem & 14 & 9.8 \\
\hline ANC & 127 & 88.8 \\
\hline Health problem not related to pregnancy & 2 & 1.4 \\
\hline \multicolumn{3}{|l|}{ Attend ANC for current pregnancy $(n=154)$} \\
\hline Yes & 142 & 92.2 \\
\hline No & 12 & 7.8 \\
\hline \multicolumn{3}{|l|}{ Number of ANC visit $(n=142)$} \\
\hline 1 & 13 & 9.2 \\
\hline $2-3$ & 111 & 78.2 \\
\hline$\geq 4$ & 18 & 12.7 \\
\hline \multicolumn{3}{|l|}{ Place ANC follow-up takes place $(n=142)$} \\
\hline Hospital & 18 & 12.7 \\
\hline Public health center & 107 & 75.4 \\
\hline Private clinic & 17 & 12.0 \\
\hline \multicolumn{3}{|l|}{ Reason of preferring this health facility $(n=142)$} \\
\hline Close to residence & 111 & 78.2 \\
\hline Fair price & 9 & 6.3 \\
\hline Competent health workers & 8 & 5.6 \\
\hline Other & 14 & 9.9 \\
\hline \multicolumn{3}{|l|}{ Time ANC follow-up started $(n=142)$} \\
\hline First trimester & 64 & 45.1 \\
\hline Second trimester & 71 & 50.0 \\
\hline Third trimester & 7 & 4.9 \\
\hline \multicolumn{3}{|l|}{ Advantage of ANC follow-up $(n=142)$} \\
\hline To assess material health conditions & 51 & 35.9 \\
\hline To assess fetal health condition & 86 & 60.6 \\
\hline To anticipate possible delivery complications & 2 & 1.4 \\
\hline I don't know the advantage & 3 & 2.1 \\
\hline \multicolumn{3}{|l|}{ Place of giving birth $(n=155)$} \\
\hline Health institution & 151 & 97.4 \\
\hline Home & 4 & 2.6 \\
\hline
\end{tabular}

\subsection{Level of maternal knowledge towards neonatal danger signs}

One hundred seventeen (75.5\%) of mothers were responding that they know about neonatal danger signs and list at least one of the ten listed key neonatal danger signs. However, only $46(29.7 \%)$ of all mothers had good knowledge which were having knowledge of at least four of the ten defined neonatal danger signs. Fever was more commonly known danger sign by $55.6 \%$ of the mothers. The response "Diarrhea", "Jaundice", "persistent vomiting" and "poor feeding" was given by $47.1 \%, 45.8 \%, 41.8 \%$ and $33.3 \%$ of the respondents respectively. The awareness 
of mothers of the remained neonatal danger signs, however, is very low which ranges from only $11.8 \%$ to $3.3 \%$ of mothers were aware of either of the remained five neonatal danger signs. The least known danger signs were abdominal distension, stated by $3.3 \%$ of the respondents (Figure 4 ).

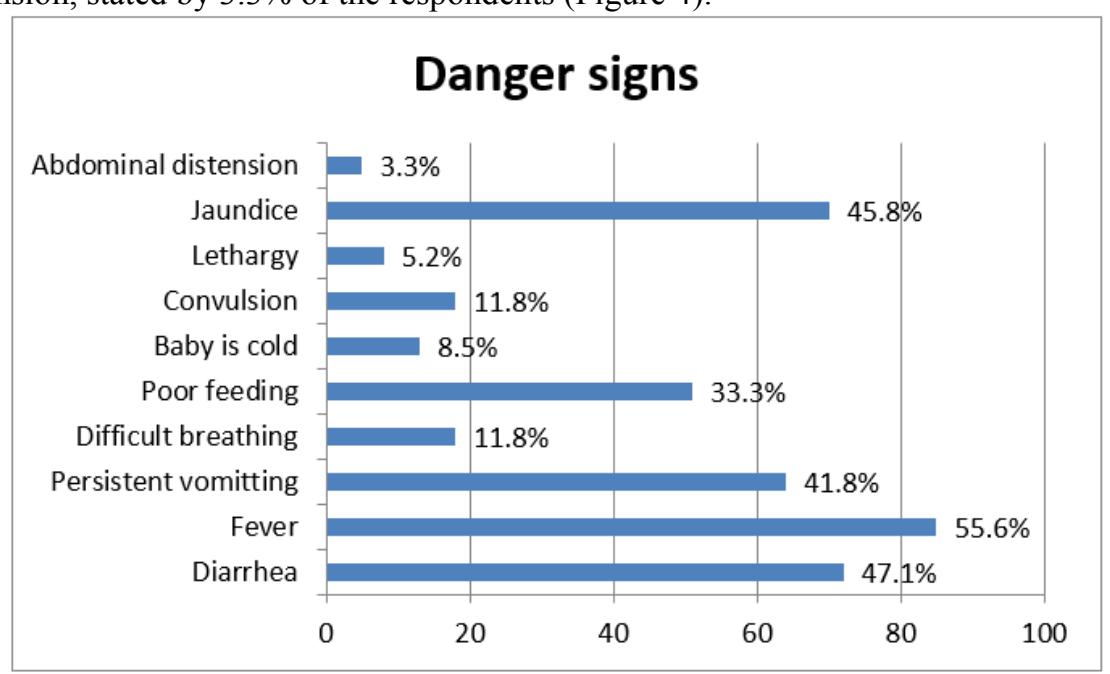

Figure 4: Distribution of respondents by types of neonatal danger signs toward in SPHMMC, Addis Ababa, Ethiopia, 2018.

\subsection{Associated factors of neonatal danger sign level of knowledge among mothers}

The level of knowledge of mothers regarding neonatal danger signs was assessed for its association with sociodemographic, pregnancy and obstetric related characteristics. The binary logistic regression model showed that the presence of functional radio was significantly associated with good knowledge level of mothers on neonatal danger signs $(\mathrm{p}=0.031)$ in which unavailability of functional radio were 2.5 times more likely to be poor knowledge of neonatal danger signs as compared to mothers who have functional radio [COR=2.48; 95\% CI $(1.09,5.66)]$. Mothers who hadn't functional Television were 9.5 times more likely to have poor knowledge of the defined neonatal danger signs than those who had functional Television [COR=9.5; 95\% CI $(1.23,73.24)]$.

Number of ANC visits ( $\mathrm{p}=0.028)$ were also statistically significant to level of knowledge about the defined neonatal danger signs. Mothers who had ANC follow up four times and above were 10 times more likely to be good level of knowledge on neonatal danger signs as compared to those mothers who had 1

ANC follow up [COR=9.96; 95\% CI $(1.28,77.60)]$. But based on multivariable logistic regression, not any factor had a significant association with the level of maternal knowledge about neonatal danger signs.

Table 3: Binary and Multivariable logistic regression analysis result of related variables to awareness level respondents to ward neonatal danger signs in SPHMMC, Addis Ababa, Ethiopia, 2018.

\begin{tabular}{|c|c|c|c|c|c|c|}
\hline \multirow[t]{2}{*}{ Characteristics } & \multirow[t]{2}{*}{ Total } & \multicolumn{2}{|c|}{$\begin{array}{l}\text { Level of maternal } \\
\text { Knowledge about neonatal } \\
\text { danger signs }\end{array}$} & \multirow[t]{2}{*}{ COR $(95 \% \mathrm{CI})$} & \multirow[t]{2}{*}{$\operatorname{AOR}(95 \% \mathrm{CI})$} & \multirow{2}{*}{$\begin{array}{l}\mathrm{P}- \\
\text { value }\end{array}$} \\
\hline & & $\begin{array}{c}\text { Poor } \\
\text { knowledge } \\
\mathrm{N}(\%)\end{array}$ & $\begin{array}{c}\text { Good } \\
\text { knowledge } \\
\mathrm{N}(\%)\end{array}$ & & & \\
\hline $\begin{array}{l}\text { Age } \\
\begin{array}{l}18-24 \\
25-30 \\
31-35 \\
>35\end{array} \\
\end{array}$ & $\begin{array}{l}34 \\
61 \\
43 \\
17 \\
\end{array}$ & $\begin{array}{l}30(88.2) \\
41(67.2) \\
25(58.1) \\
13(76.5)\end{array}$ & $\begin{array}{l}4(11.8) \\
20(32.8) \\
18(41.9) \\
4(23.5)\end{array}$ & $\begin{array}{l}1.00 \\
0.43(0.09,2.00) \\
1.59(0.46,5.49) \\
2.34(0.66,8.37) \\
\end{array}$ & $\begin{array}{l}1.00 \\
1.16(0.12,11.20) \\
3.02(0.54,17.08) \\
3.11(0.57,17.07) \\
\end{array}$ & $\begin{array}{l}0.898 \\
0.210 \\
0.191 \\
\end{array}$ \\
\hline $\begin{array}{l}\text { Marital status } \\
\text { Married } \\
\text { Single } \\
\text { Divorced } \\
\end{array}$ & $\begin{array}{l}140 \\
11 \\
4 \\
\end{array}$ & $\begin{array}{l}96(68.6) \\
10(90.9) \\
3(75.0) \\
\end{array}$ & $\begin{array}{l}44(31.4) \\
1(9.1) \\
1(25.0) \\
\end{array}$ & $\begin{array}{l}1.00 \\
1.38(0.14,13.59) \\
0.30(0.01,6.38) \\
\end{array}$ & $\begin{array}{l}1.00 \\
0.65(0.04,11.87) \\
0.20(0.01,7.60) \\
\end{array}$ & $\begin{array}{l}0.769 \\
0.385 \\
\end{array}$ \\
\hline $\begin{array}{l}\text { Religion } \\
\text { Orthodox } \\
\text { Catholic } \\
\text { Protestant } \\
\text { Muslim }\end{array}$ & $\begin{array}{l}84 \\
4 \\
42 \\
25\end{array}$ & $\begin{array}{l}64(76.2) \\
1(25.0) \\
26(61.9) \\
18(72.0)\end{array}$ & $\begin{array}{l}20(23.8) \\
3(75.0) \\
16(38.1) \\
7(28.0)\end{array}$ & $\begin{array}{l}1.00 \\
0.80(0.29,2.20) \\
7.71(0.68,87.25) \\
1.58(0.54,4.62)\end{array}$ & $\begin{array}{l}1.00 \\
0.47(0.11,2.03) \\
0.48(0.02,11.74) \\
0.56(0.13,2.48)\end{array}$ & $\begin{array}{l}0.313 \\
0.655 \\
0.443\end{array}$ \\
\hline
\end{tabular}




\begin{tabular}{|c|c|c|c|c|c|c|}
\hline $\begin{array}{c}\text { Family size } \\
1-3 \\
4-6 \\
7-10\end{array}$ & $\begin{array}{l}77 \\
68 \\
5 \\
\end{array}$ & $\begin{array}{l}61(79.2) \\
44(64.7) \\
4(80.0)\end{array}$ & $\begin{array}{l}16(20.8) \\
24(35.3) \\
1(20.0)\end{array}$ & $\begin{array}{l}1.00 \\
1.05(0.11,10.04) \\
2.18(0.23,20.63)\end{array}$ & $\begin{array}{l}1.00 \\
0.47(0.02,11.42) \\
0.54(0.02,14.15)\end{array}$ & $\begin{array}{l}0.645 \\
0.711 \\
\end{array}$ \\
\hline $\begin{array}{l}\text { Functional radio } \\
\text { Yes } \\
\text { No }\end{array}$ & $\begin{array}{l}105 \\
50\end{array}$ & $\begin{array}{l}68(64.8) \\
41(82.0) \\
\end{array}$ & $\begin{array}{l}37(35.2) \\
9(18.0)\end{array}$ & $\begin{array}{l}1.00 \\
2.48(1.09,5.66)\end{array}$ & $\begin{array}{l}1.00 \\
3.23(0.91,11.48)\end{array}$ & 0.070 \\
\hline $\begin{array}{l}\text { Functional } \\
\text { Television } \\
\text { Yes } \\
\text { No } \\
\end{array}$ & $\begin{array}{l}135 \\
20\end{array}$ & $\begin{array}{l}90(66.7) \\
19(95.0)\end{array}$ & $\begin{array}{l}45(33.3) \\
1(5.0)\end{array}$ & $\begin{array}{l}1.00 \\
9.50(1.23,73.24)\end{array}$ & $\begin{array}{l}1.00 \\
15.30(0.73,322.2)\end{array}$ & 0.079 \\
\hline $\begin{array}{l}\text { Functional } \\
\text { telephone } \\
\text { Yes } \\
\text { No }\end{array}$ & $\begin{array}{l}147 \\
8\end{array}$ & $\begin{array}{l}102(69.4) \\
7(87.5)\end{array}$ & $\begin{array}{l}45(30.6) \\
1(12.5)\end{array}$ & $\begin{array}{l}1.00 \\
3.09(0.37,25.84)\end{array}$ & $\begin{array}{l}1.00 \\
0.42(0.01,17.34)\end{array}$ & 0.650 \\
\hline $\begin{array}{l}\text { Died children } \\
\text { No } \\
\text { Yes } \\
\end{array}$ & $\begin{array}{l}132 \\
20 \\
\end{array}$ & $\begin{array}{l}90(68.2) \\
16(80.0) \\
\end{array}$ & $\begin{array}{l}42(31.8) \\
4(20.0)\end{array}$ & $\begin{array}{l}1.00 \\
1.87(0.59,5.92) \\
\end{array}$ & $\begin{array}{l}1.00 \\
0.67(0.14,3.27)\end{array}$ & 0.621 \\
\hline $\begin{array}{l}\text { Number of ANC } \\
\text { visit } \\
1 \\
2-3 \\
\geq 4\end{array}$ & $\begin{array}{l}13 \\
111 \\
18\end{array}$ & $\begin{array}{l}10(76.9) \\
70(63.1) \\
17(94.4)\end{array}$ & $\begin{array}{l}3(23.1) \\
41(36.9) \\
1(5.6)\end{array}$ & $\begin{array}{l}1.00 \\
5.10(0.47,55.89) \\
9.96(\mathbf{1 . 2 8 , 7 7 . 6 0 )}\end{array}$ & $\begin{array}{l}1.00 \\
18.20(0.99,334.8) \\
12.26(0.99,151.2)\end{array}$ & $\begin{array}{l}0.051 \\
0.051\end{array}$ \\
\hline $\begin{array}{l}\text { Place of ANC } \\
\text { F/up } \\
\text { Hospital } \\
\text { Health center } \\
\text { Clinic }\end{array}$ & $\begin{array}{l}18 \\
107 \\
17\end{array}$ & $\begin{array}{l}12(66.7) \\
71(66.4) \\
14(82.4)\end{array}$ & $\begin{array}{l}6(33.3) \\
36(33.6) \\
3(17.6)\end{array}$ & $\begin{array}{l}1.00 \\
2.33(0.48,11.40) \\
2.37(0.64,8.76)\end{array}$ & $\begin{array}{l}1.00 \\
2.24(0.28,11.97) \\
2.63(0.41,16.78)\end{array}$ & $\begin{array}{l}0.448 \\
0.305\end{array}$ \\
\hline
\end{tabular}

\section{Discussion}

The purpose of this study was to assess the level of maternal knowledge towards neonatal danger signs and associated factors among mothers attending in SPHMMC. In this study it was found that almost one third (29.7\%) of mothers were having good level of knowledge of at least four of ten listed neonatal danger signs. This finding is nearly similar to the study focused on the awareness of mothers in Ghana 2013 [16] which was $28.3 \%$ and the awareness in different regions (Tigray, Oromia, Amhara and SNNP) of Ethiopia [10] which was 29.3\%. But this result is lower than to the study in north India [2] which was 50\% and study conducted on aware of mothers at least three danger signs in rural Wardha, India [10] which was $67.4 \%$. This may be associated with the information on danger sign was not adequately disseminated to mothers both during antenatal and PNC period [20].

This study showed that "fever" is the commonest known neonatal danger sign which is reported by $55.6 \%$ of the mothers. This finding is lower than the findings in peri urban Wardha, India (2008) [13] which was reported by $76.4 \%$, Luck know City India (2006) [14] which was reported by $76.9 \%$, Ghana (2013) [15], and in the previous study in different regions of Ethiopia (2012) [11] which was reported by $83.6 \%$ of the mothers. The reason behind might be due to this sign is easily identified by touching the body of infants and mothers experienced that if fever cannot be reduced the infants situation aggravated.

This study confirmed that ANC follow up practice creates a good opportunity for the mother to have good knowledge towards neonatal danger sign. Mothers, who attend ANC four and above, were ten times more likely to mention at least four neonatal danger sign as compared to their counterparts. Even though the finding is different from the study conducted in Uganda [15], there are explanations which support the current finding. The possible and the best reason for this could be mother's exposure to ANC package, which increased the knowledge of the mother concerning the neonatal danger signs.

An increased exposure to media especially radio and television was also increased the knowledge of mothers on neonatal danger signs. Availability of functional radio were 2.5 times more knowledgeable than their counterparts; similarly Television exposed mothers were 9.5 times more knowledgeable than their accompaniment and this is supported by a study conducted in Ghana [14]. This could be radio and television contains a segment of airtime dedicated to teach the community about health issue of mothers and children. Using such media could also increase the memorability of the message.

In this study age, parity and educational status of mother were not significantly associated with knowledge about neonatal dangers signs. This is unlike with studies done in Nairobi, India and central Bangalore, Egypt, Sri -Lanka and Ethiopia [17-19]. The reason for this difference may be due to the case that health care providers 
deliver health information or counseling about neonatal danger signs regardless of age, parity and educational status of mother.

\section{Conclusion and Recommendations}

\subsection{Conclusion}

Although Ethiopia has taken great initiative to empower the community to improve neonatal and infant health services at community level, maternal knowledge level about neonatal danger signs was found to be poor. But more than two third of mothers had poor awareness of the neonatal danger signs and majority of them did not aware either of baby is cold, difficulty of breathing, abdominal distension, lethargy and convulsion as neonatal danger signs. In the bivariate logistic regression analysis; availability of functional radio and television, number of ANC were significantly associated with awareness of neonatal danger signs.

\subsection{Recommendations}

Based on the study findings the following recommendations are forwarded:

- It is better if the health care providers work on postnatal counseling at health facilities aimed to increase the mothers' level of knowledge of different neonatal danger signs.

- It is also recommended if the HEWs provide health information regarding neonatal danger signs at community level to increase level of knowledge among mothers.

- It is well again if the stakeholders (FMOH, RHB and NGOs) strengthen and sustain the existing newborn care strategies, and approaches for further improvement of knowledge level of mother's towards neonatal danger signs.

\section{Acknowledgements}

We would like to thank St' paul's hospital millinium medical college, neonatal nursing department and hospital staffs particularly postnatal ward staffs for their cooperation to conduct the data collection. We would like to express our heart full gratitude for our colleagues Ayalnesh Zemene and Ermias Dereje for their support during the whole process.

\section{Disclosure}

The author reports no conflicts of interest in this work.

\section{References}

1. UNICEF Committing to child survival: A Promise Renewed. Progress Report 2014.

2. Shally Awasthi, Tuhina Verma, and Monica Agarwal: Danger signs of neonatal illnesses; perceptions of caregivers and health workers in northern India, 2010.

3. EDHS, Ethiopia Demographic and Health Survey 2016.

4. Gebeyaw Molla, Alemayehu Goine, Terefa Balchew and Bitiya Admasu, community based cross sectional study: Health care seeking behaviour on neonatal danger signs among mothers in Tenta District, Northeast Ethiopia, 2017.

5. Solomon Gedlu and Abel Fikadu, community based study, Level of mother's knowledge about neonatal danger signs and associated factors in North West of Ethiopia, 2012.

6. Walellign Anemut, Bekana Fekecha and Tigist Demeke: Mother's knowledge and Practice about Neonatal Danger Signs and Associated Factors in Wolkite Town, Gurage Zone, SNNPR, Ethiopia, 2017.

7. Nuredin Adem, Kalayoy K, and Yohanness Tesfaye: Awareness and Associated Factors towards Neonatal Danger Signs among Mothers Attending Public Health Institutions of Mekelle City, Tigray, Ethiopia, 2015.

8. Anwar-ul-Haq, Hameed Mumtaz Durrani, Ramesh Kumar, Salma Mumtaz Durrani: Recognizing the Danger Signs and Health Seeking Behaviour of Mothers in Childhood Illness in Karachi, Pakistan, 2015.

9. Kuganab-Lem, Adadow Yidana: Exploring Women Knowledge of Newborn Danger Signs; A Case of Mothers with under Five Children Robert Tamale, Ghana, 2014.

10. Lawn JE, Kerber K, Enweronu-Laryea C, Cousens S: 3.6 million neonatal deaths-what is progressing and what is not? Semin Perinatol 34:371-386, 2010.

11. Bhargava SK: The Challenges of Neonatal Mortality in India. Indian Pediatr 41: 657-662, 2004.

12. Dongre AR, Garg BS: Perceptions and health care seeking about newborn danger signs among mothers in rural Wardha, India. Indian J Pediatr 75: 325- 329, 2006.

13. Padiyath MA, Bhat VB, Ekambaram M: Knowledge attitiude and practice of neonatal care among postnatal mothers. Curr Pediatr Res 14:147-157, 2010.

14. Young Infants Clinical Signs Study Group: Clinical signs that predict severe illness in children under age 2 months: a multicentre study. Lancet 371: 135-142, 2008.

15. Sandberg J, Odberg Pettersson K, Asp G, Kabakyenga J, Agardh A: Inadequate knowledge of neonatal danger 
signs among recently delivered women in Southwestern Rural Uganda: a community survey. PloS One 9(5):e97253, 2014. doi:10.1371/journal.pone.0097253

16. Hill Z, Kendall C, Arthur P, Kirkwood B, Adjei E: Recognizing childhood illnesses and their traditional explanations: exploring options for care-seeking interventions in the context of the IMCI strategy in rural Ghana. Trop Med Int Health 8(7):668-676, 2003

17. Nigatu, S. G., A. G. Worku, and A. F. Dadi, Level of mother's knowledge about neonatal danger signs and associated factors in North West of Ethiopia: a community based study. BMC Research Notes 2015. 8: p. 309.

18. Assefa, F. M., Assessment of Knowledge and Health Care Seeking Behavior about Neonatal Danger Signs among Mothers Visiting Immunization Unit Inselected Governmental Health Centers, Addis Ababa, Ethiopia. Msc Thesis, Addis Ababa University, Addis Ababa. 2014.

19. Gathoni, A., Mother's Knowledge, Attitude and Practice Regarding Neonatal Illness and Assessment of Neonates at Kenyatta National Hospital, Msc Thesis, University of Nairobi, Nairobi. 2013.

20. Kibaru EG, Otara AM. Knowledge Of neonatal danger signs among mothers attending well baby clinic in Nakuru Central District, Kenya: cross sectional descriptive study. BMC Res Notes. 2016;9(1):481.

21. Abera Mersha, Nega Assefa, Kedir Teji, Agegnehu Bante, Shitaye Shibiru.Mother's Level of Knowledge on Neonatal Danger Signs and Its Predictors in Chencha District, Southern Ethiopia. American Journal of Nursing Science, 2017; 6(5): 426-432 http://www.sciencepublishinggroup.com/j/ajns doi: 10.11648/j.ajns.20170605.17 ISSN: 2328-5745 (Print); ISSN: 2328-5753 (Online) 